\title{
A Virtual Mirror for Self-Knowledge Activities with People with Down Syndrome
}

\author{
Guilherme Guimarães Vaz \\ Pontifícia Universidade \\ Católica de Goiás, PUC Goiás \\ Goiânia, Brazil
}

\section{Luciana Novais de Oliveira Brito \\ Pontifícia Universidade \\ Católica de Goiás, PUC Goiás \\ Goiânia, Brazil}

\author{
Lutyéllen dos Santos \\ Ribeiro \\ Pontifícia Universidade \\ Católica de Goiás, PUC Goiás \\ Goiânia, Brazil \\ Olegário Correa da Silva \\ Neto \\ Pontifícia Universidade \\ Católica de Goiás, PUC Goiás \\ Goiânia, Brazil
}

\author{
Mariana Fernandes da \\ Cunha \\ Pontifícia Universidade \\ Católica de Goiás, PUC Goiás \\ Goiânia, Brazil \\ Talles Marcelo Gonçalves \\ de Andrade Barbosa \\ Pontifícia Universidade \\ Católica de Goiás, PUC Goiás \\ Goiânia, Brazil
}

\begin{abstract}
People with Down Syndrome have peculiar physical and cognitive characteristics due to genetic alterations. Given this, self-knowledge is essential for identity formation. Recently, it is possible to use technological resources that facilitate the application of therapeutic and educational activities. This paper proposes a system called Virtual Mirror, which enables activities that stimulate self-knowledge. Previously programmed questions are reproduced by the mirror, concomitantly with the projection of user images. After that, the system waits for responses, evaluates agreement and consistency, and issues a response to the user in the form of greetings. Also, the Virtual Mirror provides a channel for biofeedback. It analyzes user behavior during the execution of each activity. Twenty-seven volunteers evaluated the virtual mirror, people with Down Syndrome, male and female, aged 13 to 51 years. It was done at the Pontifical Catholic University of Goiás (PUC Goiás), in the space reserved for the activities of the Alfadown project, an extension project maintained by PUC Goiás. The results showed that the virtual mirror had $77.14 \%$ of agreement and $55 \%$ for consistency. Through facial expressions, it was possible to reach an average of over $95 \%$ for visual attention throughout activities. It shows that the proposed tool has the potential for use with the Down Syndrome population.
\end{abstract}

\section{General Terms}

Down Syndrome, Virtual Mirror, Self-Knowledge Activities.

\section{Keywords}

Down Syndrome, Virtual Mirror, Self-Knowledge Activities.

\section{INTRODUCTION}

Down syndrome (DS) is a genetically determined human condition, is the most common alteration in humans and the leading cause of intellectual disability in the population. SD is a way of being in the world that demonstrates human diversity. People with DS, when adequately treated and stimulated, are known to have the potential for a healthy life and full social inclusion [1].

The Alfadown Project is an extension project at the Pontifical Catholic University of Goiás (PUC-Goiás) that aims to aid the process of literacy and literacy of people with Down
Syndrome, using the computer as an educational tool, and also enable, the development of social skills [2].

Nowadays, different technologies are used for the rehabilitation and training of people with DS. Lori's Help [3] is an application that facilitates literacy by offering letter and word matching. AlfaPlay is a device to aid in the development of stick writing [4]. The sociable robot [5] for psychomotor training activities.

Graphics and virtual elements can stimulate visual attention, perception, engagement, and pleasure. At the same time, computing devices can be developed or customized to meet these requirements. Also, they can be automatically readjusted through a biofeedback channel, from which variables that reflect user behavior can be extracted while performing activities.

The self-knowledge through the mirrors allows maintaining the participant's attention and interest in the proposed activity. Virtual Reality for Pediatric Neuro-Rehabilitation project [6] offers a virtual mirror to attract children's interest in sensorimotor therapy activities. Also, The Virtual Mirror Therapy system provides a mirror interface system to assist people after stroke [7].

This paper presents a virtual mirror to support self-knowledge activities with the Down Syndrome population. As a result, the system software offers questions and processes the answers in which to stimulate the user. All questions and answers were prepared and previously evaluated jointly with a multidisciplinary team. At the end of the activity, the software presents reports to describe functional and behavioral performance for each participant.

\section{MATERIALS AND METHODS}

The software development process was based on the incremental model. It was chosen due to the need for refinement of requirements along the process because requirements are incomplete at the beginning. Figure 1 shows the software development process activities. 


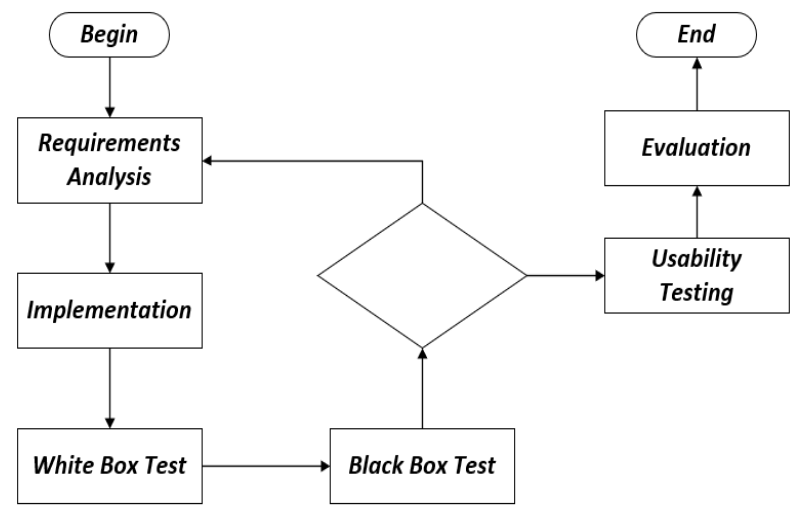

Fig 1. Software Development Process Diagram.

\subsection{Requirement Analysis}

The requirement analysis activity was performed after weekly meetings with an interdisciplinary team composed of professionals of Speech Therapy, Psychology, and Computer Engineering. After that, software preliminarily versions were produced. Figure 2 shows the user interface evaluated on usability testing. The choice of colors and the arrangement of objects aimed to draw the user's attention and facilitate the visualization of the interface elements.

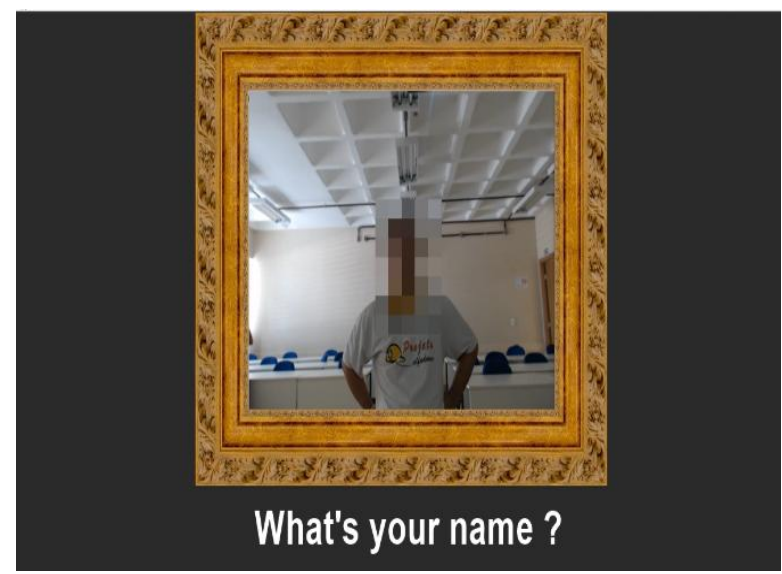

Fig 2. Virtual Mirror Interface.

Figure 2 shows one self-knowledge question presented to the users. All self-knowledge questions were presented in a written and oral way. All items were previously defined and evaluated by psychologists and speech therapists to stimulate self-knowledge. In usability testing, the virtual mirror system was already programmed to reproduce the following questions: (a) What is your name?, (b) How old are you ?, (c) Who are your friends?, (d) What can you do on your own?, and (e) Which place do you like to go for a walk?

The user's answers were converted to text format to verify the agreement and consistency, comparing the actual response to the previously annotated through recruitment activity shown in Fig. 5. Besides, for some questions, the system should be able to classify the participant's response into fourth categories: child, adolescent, youth, and adult, such as "How old are you?". All answers issued by the Virtual Mirror feature a hearty greeting accompanied by an image. It is used as a visual reinforcement and aims to stimulate visual attention, engagement, and user satisfaction during the execution of the activity.

\subsection{Software Building (Implementation)}

In the implementation stage, the Python programming language was used, with libraries, OpenCV, and Pyttsx3. The agreement and consistency of user responses were assessed using the Google Speech Recognition API, which can convert audio (from Microphone) to text (String) in the Portuguese language.

The voice recognition module performs the agreement of response. In the meantime, consistency assesses whether what was answered by the participant matches the issue addressed in the question.

To record the videos, with the images of the participants reproduced during the activities such as shown in Figure 2, the OpenCV library was used. It enables the creation of files in various encoding formats, for example, AVI, MP4, and MKV. These files are used posterior by the Emolab tool [8] for extraction and analysis of the variables that show the participant's behavior throughout the activity.

Questions were presented to participants in text and audio format. For this, the Pyttsx 3 library was used. It allows the sound reproduction of a text, in String format. Also, the QThread library was used to control concurrency among the software functionalities.

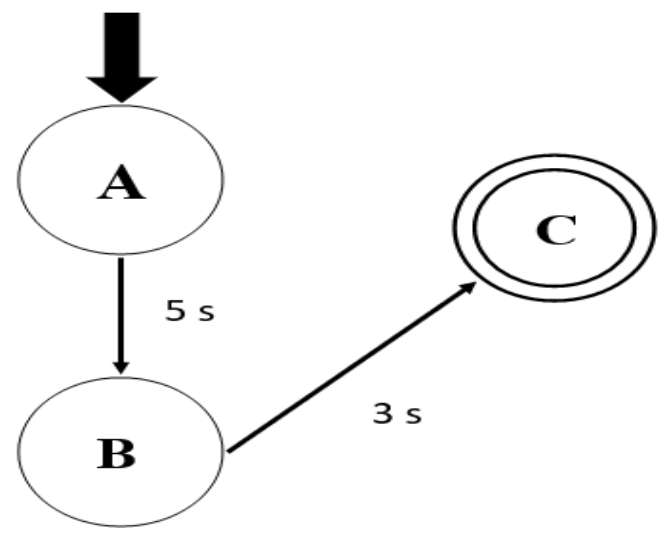

Fig 3. State Diagram

Each state (Figure 3 ) represents the type of action performed by the software. State "A", the Virtual Mirror asks questions to the participant. In-state "B", the Virtual Mirror recognizes the response issued by the user. In-state "C", the Virtual Mirror issues the answer to the user. Transitions represent the time to wait between each activity. The automaton is shown in Fig. 3 is executed for each question entered into the system.

\subsection{Test White and Black Box}

During the weekly meetings, tests were performed on the requirements validation tool. The project team made these to test all functionality.

At first, the tests verified software coding (White Box Test) to find errors in the programming logic. After validating the coding, the tests confirmed the usability of the tool (Black Box Test) in pilot tests with the members of the development team.

\subsection{Usability Testing}

Figure 4 illustrates the testing environment, highlighting the equipment used. It is a private room located in PUC Goiás in the same building where the Alfadown project activities take place. In Fig. 4, the multimedia projector (A) was installed in 
the upper part of the room. The webcam (B) was positioned so that it could capture images of each participant's face.

Data collection took place on two different days. Twentyseven students of the Alfadown project, male and female, aged 13 to 51 years old, participated in this study.

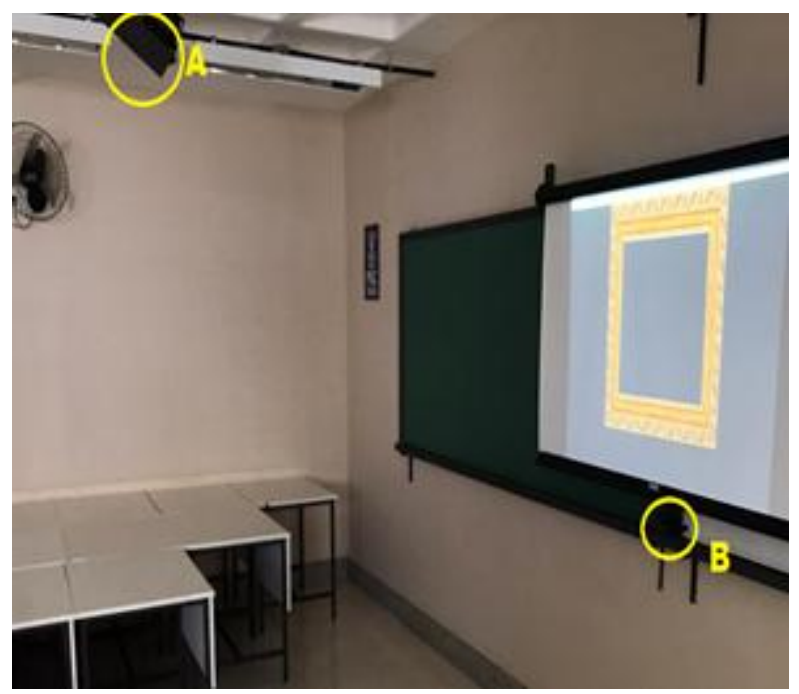

Fig 4. Test Environment.

The testing process with the volunteers is described by the diagram shown in Figure 5. To this end, the volunteer was invited to participate while participating in other daily activities offered by the Alfadown project. Given this, the research team briefly interrupted the current activity, presented the project, verified the understanding of the interested parties, and selected those who expressed interest in participating. Then, individually, each volunteer was taken to a private room, shown in Fig. 4. At this location, they were received by a team of two speech therapists, for the application of an evaluation quiz and then the tests. At any time, if the volunteer showed disinterest, discomfort, or intention not to continue, the test should be discontinued, and the volunteer would be returned to the routine activities offered by the Alfadown project.

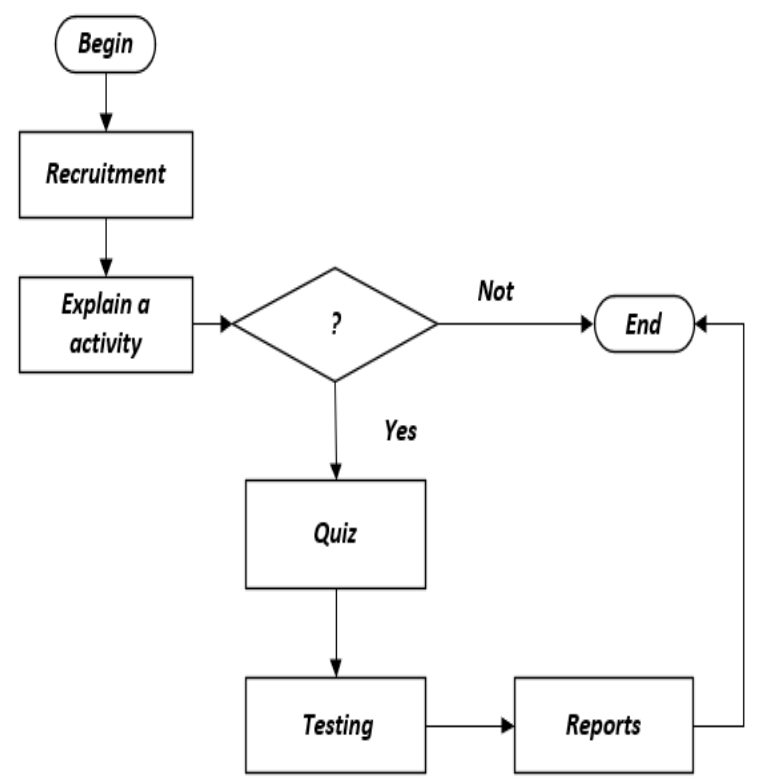

Fig 5. Activity Diagram.
The quiz applied during activity is described in Figure 6. The software and the exam have the same questions.

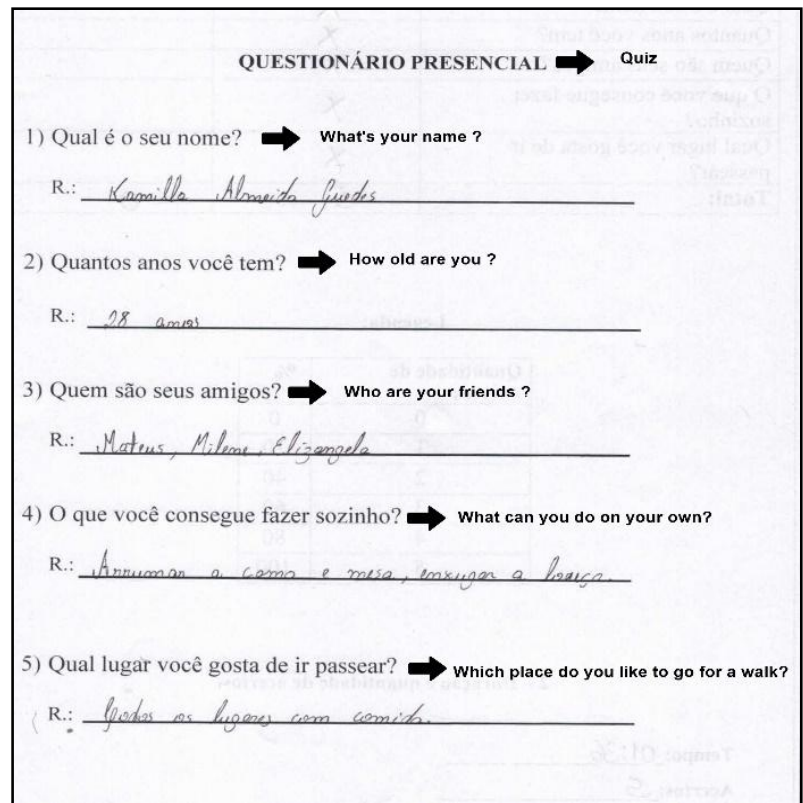

Fig 6. Quiz.

The tests were performed individually, in a private room, to avoid embarrassment and ensure confidentiality to the research participant. In addition to the researchers, only each participant's parents were invited to attend. At the end of the activity, the software provides reports for subsequent analysis.

The image of Figure 7 was captured during the execution of the activity. On the left side, a female participant receives the Virtual Mirror sound greeting. On the right side, Figure 7 illustrates how the participant views the software interface.

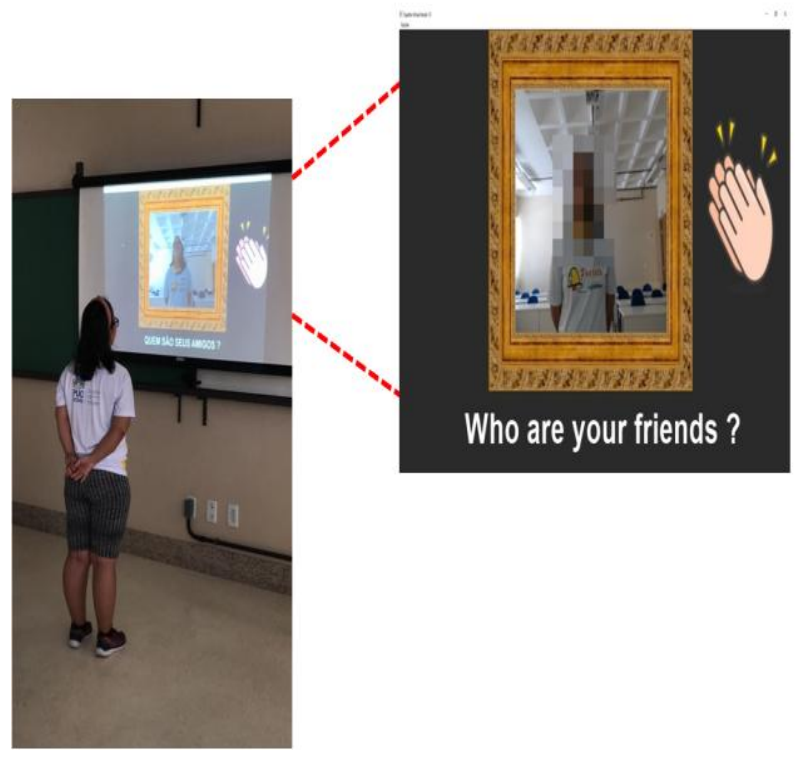

Fig 7. The implementation of the tests.

\section{RESULTS}

For data analysis, the video files provided by the Virtual Mirror were used. From these, variables and data were extracted that reflect the behavior of each research participant For this, we used the Emolab tool, developed at PUC Goiás for the Android platform, capable of performing video 
processing and generating reports for posterior analysis. The application allows you to observe variables such as Attention, Engagement, Disgust, and Joy.

Table 1 shows the results obtained after processing the videos in the Emolab tool. The columns in this table show the variables selected for analysis and present the mean, calculated over time. It was considered the total time that each participant consumed during the execution of the activity. The character $(*)$ represents the absence of the facial movement of this variable.

The tool analyzed the expressions of eighteen participants. Nine participants were eliminated from the analyzes. These were rejected by not looking towards the Virtual Mirror during the activity.

The Attention variable is estimated by the focus of the vision concerning the orientation of the head. The Engagement verifies the activation of the facial muscles by the expression presented by the participant. The variable Valence reflects the participant's experience while the Surprise is estimated by the mouth opening and chin drop movement.

The Valence variable is the only variable rated from -100 (lowest score) to 100 (highest rating). The other variables are measured from 0 (lowest score) to 100 (highest score).

Table 1. Variables analyzed

\begin{tabular}{|c|c|c|c|c|c|c|c|}
\hline ticipant & Attention & Engagement & Valence & Disgust & Fear & Joy & Sadness \\
\hline 1 & 95 & 58,75892857 & 37,46642857 & 0,4375 & * & 43,83035714 & * \\
\hline 2 & 97,49179207 & 24,67852257 & $-1,292749658$ & 0,150478796 & * & * & 0,011627907 \\
\hline 3 & 93,14705882 & 21,42339261 & $-3,241450068$ & 3,249658003 & * & 0,756497948 & 0,22366621 \\
\hline 4 & 87,00896861 & 63,73766816 & 34,650224222 & 1,511210762 & $*$ & 44,34304933 & $*$ \\
\hline 5 & 95,56853933 & 27,76404494 & 18,2988764 & 2,173033708 & * & 21,67865169 & * \\
\hline 6 & 97,30630631 & 53,38063063 & -35,59459459. & 47,80855856 & 1,2252252525 & * & * \\
\hline 7 & 63,77200903 & 23,86004515 & 6,785553047 & 0,936794582 & * & 15,77363431 & * \\
\hline 8 & 89,25956567 & 10,92657704 & $-2,255429162$ & 1,979317477 & 1,412616339 & 0,755946225 & 0,004136505 \\
\hline 9 & 94,34553464 & 24,08066184 & $-0,961773732$ & 1,518097208 & 0,001034126 & 3,366080662 & * \\
\hline 10 & 97,01758014 & 7,347466391 & $-6,846949328$ & 0,556359876 & * & * & * \\
\hline 11 & 95,44444444 & 57,54320988 & 51,13580247 & * & 9,925925926 & 50,45679012 & * \\
\hline 12 & 97,27027027 & 71,27027027 & 31,10810811 & 1,432432432 & * & 62,1621622 & * \\
\hline 13 & 97,41414944 & 53,839427766 & 23,1200318 & 0,882352941 & 0,026232114 & 22,36645469 & * \\
\hline 14 & 88,01219512 & 4,323170732 & $-0,015853659$ & 0,774390244 & 0,134146341 & * & 0,115853659 \\
\hline 15 & 92,70460048 & 7,130750605 & $-2,479418886$ & 0,04842615 & * & 2,946731235 & * \\
\hline 16 & 93,03690561 & 27,20936835 & $-6,287437899$ & 11,03548616 & 0,001419446 & 3,46912704 & * \\
\hline 17 & 64,12785388 & 36,50913242 & $-10,47945205$ & 21,62100457 & * & 9,993150685 & * \\
\hline 18 & 96,477183099 & 7,059859155 & $-0,461267606$ & 0,238732394 & 0,014084507 & * & * \\
\hline & & 090205 & & & & & \\
\hline
\end{tabular}

Figures $8,9,10$, and 11 illustrate the behavior of the variables for participant 12 during the activity. The participant was chosen because it presented greater expressiveness, compared to the other participants of the research. The graphics are in the time domain. The $\mathrm{Y}$-axis represents the score of the variable ( 0 to 100). The $\mathrm{X}$-axis represents the period of execution of the activity. The red dotted line in the graphs represents the simple arithmetic mean for each variable.

The Attention variable (Figure 8), during the activity, had a score above 90 points. It reflects the focus that the participant had on the Virtual Mirror.

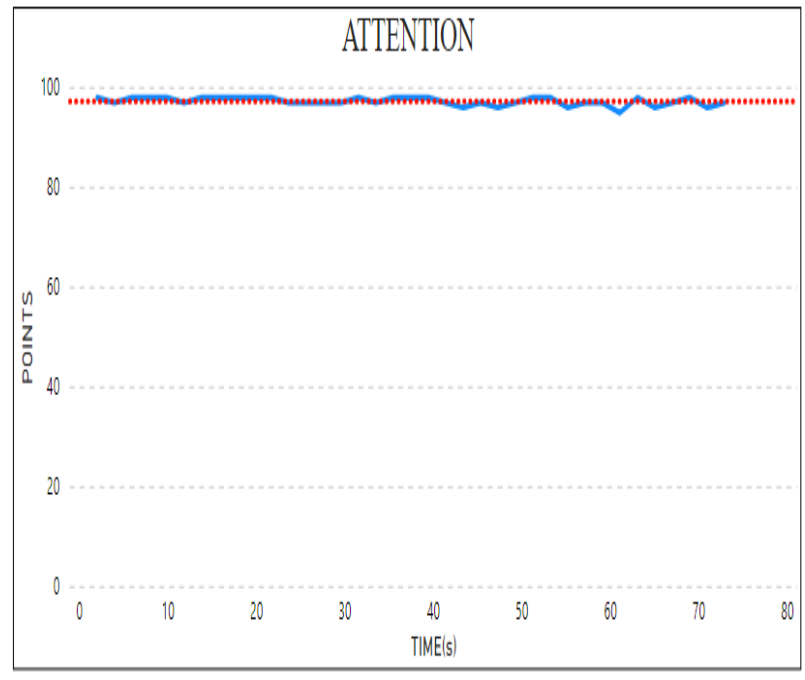

Fig 8. The attention of the participant in the activity.

The participant presented a higher average of Engagement (Figure 9) than the other participants, reflecting their expressiveness during the activity.

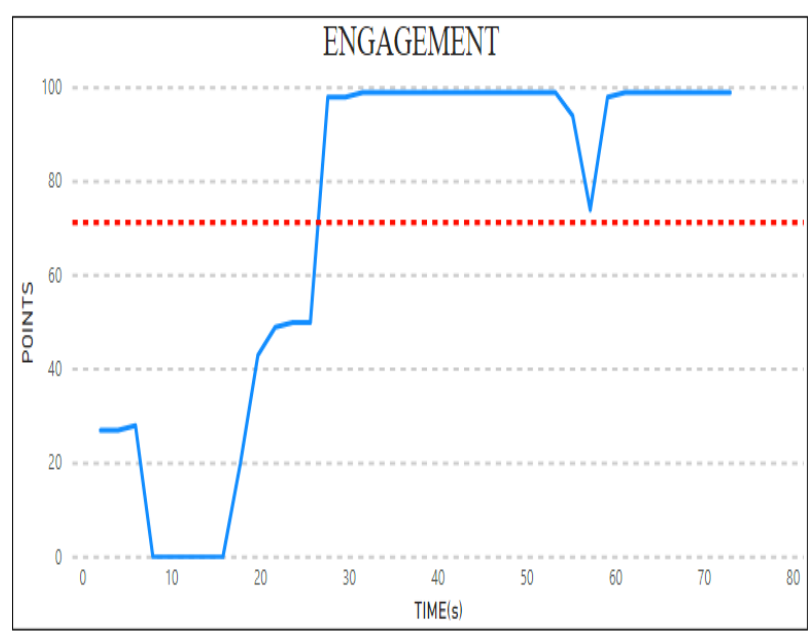

Fig 9. Engagement of the participant in the activity.

The Joy variable (Figure 9) showed a score after the first Virtual Mirror sound salute, reaching 62 points of average. The graph shows a drop in this variable caused by the participant's focus on the question "What can you do alone?".

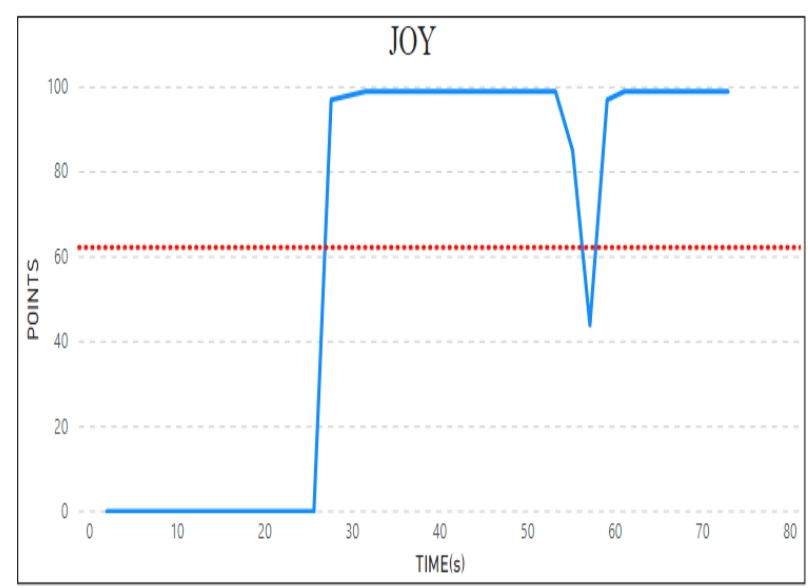

Fig 10. The joy of the participant in the activity. 
The Disgust variable (Figure 11) presented the first score above 10 points, which relates to the first contact with the Virtual Mirror, in which the participant understood the purpose of the activity. Other variables did not show significant movement for plotting the graph.

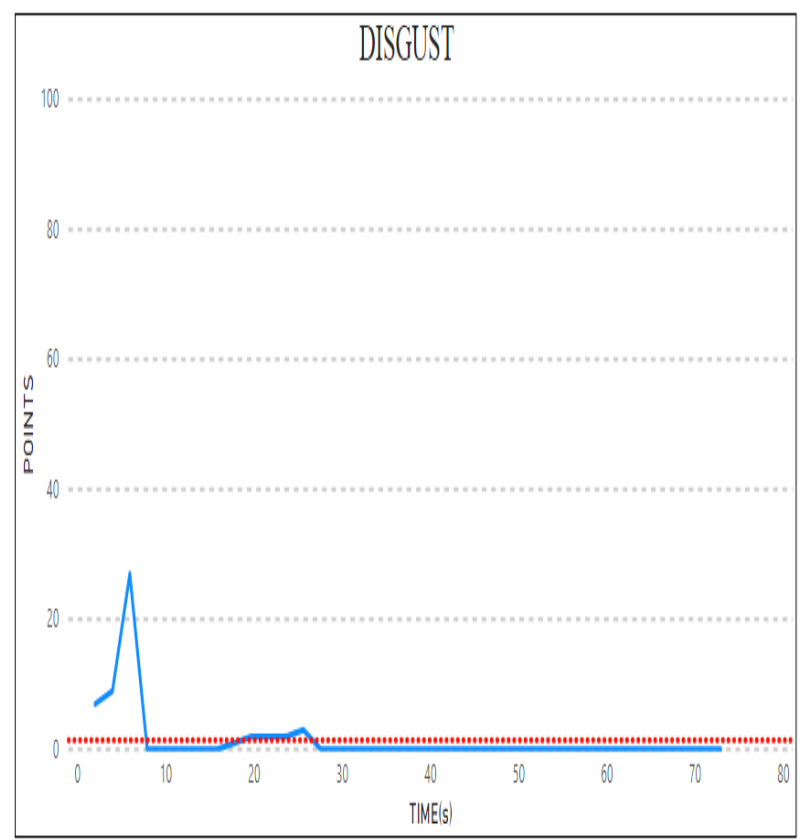

Fig 11. The disgust of the participant in the activity.

The text file provided by the tool was used to analyze the responses issued by the participant. It contains the answers collected in each question.

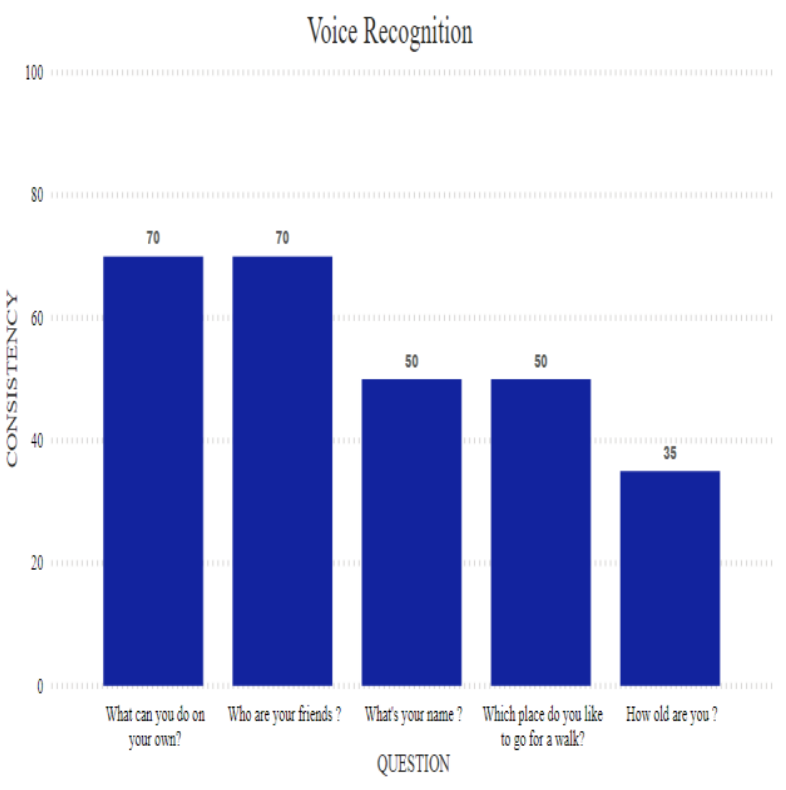

Fig 12. Voice Recognition.

The graph (Figure 12) illustrates the analysis made on each type of question. In this graph, the software consistency was evaluated. The $\mathrm{X}$-axis represents the questions issued by the Virtual Mirror. The Y-axis represents the percentage of answers recognized by the software in that type of question. Participant response was not identified in the following cases when no response was captured or the participant responded before an activity state change (software failure).

\section{Coherence of Response}

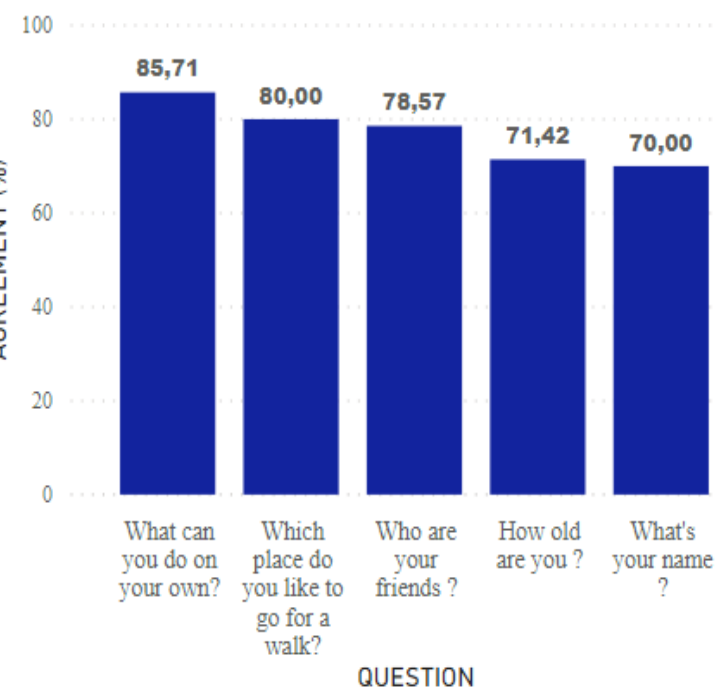

Fig 13. The coherence of response.

The graph (Figure 13) illustrates the coherence percentage of participant responses. In this graph, it was evaluated if the answer matches the subject matter and its integrity. For the questions, "What's your name? "and what's your age? "We used data provided by the project coordination. These data present the correct name and age of the participants. These questions showed a percentage of $70 \%$ and $71.42 \%$, respectively.

Some participants did not see themselves at the correct age, and others answered the name of a favorite artist or character. The answers obtained influenced the percentage of these two questions. The remaining items reached a rate higher than $75 \%$ of coherence.

\section{CONCLUSION}

This paper presents a software system to assist people with Down syndrome to improve their self-awareness and selfconsciousness. The results show that the software reached a percentage of agreement of $77.14 \%$ and $55 \%$ for consistency in the answers issued by the participants. Through facial expressions, it was possible to reach an average of over $95 \%$ for visual attention during the whole activity. It reveals that the proposed tool has the potential for use with the Down Syndrome population. Besides, with the data obtained, the project volunteers verify how the student sees himself or herself as a person, allowing them to enjoy the project activities.

\section{ACKNOWLEDGMENTS}

The authors thank the Goiás Research Support Foundation (FAPEG) for their financial support.

\section{REFERENCES}

[1] Pessoa com Síndrome de Down. Diretrizes de Atenção. MINISTÉRIO DA SAÚDE. Brasília - DF. 2013. 1a edição.

[2] Programa de Referência em Inclusão Social. available in: $<$ https://sites.pucgoias.edu.br/extensao/coordenacoes/coo rdenacao-de-extensao/programa-de-referencia-eminclusao-social/>. 
[3] Lima D.; Araújo, R.; Souza, M.; ROCHA, Adson Ferreira da; Hannum, J.; A. BARBOSA, TALLES MARCELO G. DE. Software with Biofeedback to Assist People with Down Syndrome. International Journal of Computer Applications, v. 158, p. 31-37, 2017.

[4] RODRIGUES, M. L. et al. Alfaplay - Uma ferramenta para Auxiliar na Alfabetização de Pessoas com Síndrome de Down. Goiânia.

[5] CANDIDO, JARDEL; CECÍLIA, KÁRITA; RUBEN, ARIANE; SANTOS, JULIANA; DOUGLAS, EDSON; MARCELO, TALLES. Robot Dancer for Activities with People with Down Syndrome. INTERNATIONAL JOURNAL OF COMPUTER APPLICATIONS, v. 178, p. 35-39, 2019.

[6] Kommalapati, Roopeswar \& Michmizos, Konstantinos. Virtual Reality for Pediatric Neuro-Rehabilitation: Adaptive Visual Feedback of Movement to Engage the
Mirror Neuron System. Conference proceedings: Annual International Conference of the IEEE Engineering in Medicine and Biology Society. IEEE Engineering in Medicine and Biology Society. Conference. 2016. 10.1109/EMBC.2016.7592058.

[7] Grafe (Pälmke), Marion \& Piekartz, Harry \& Zalpour, Christoff \& Schüler, Thomas \& Morisse, Karsten. (2009). A new perspective for Virtual Mirror Therapy Developing a low-cost-high-convenient environment utilizing the Wiimote. 197 - 197. 10.1109/ICVR.2009.5174235

[8] Santos, D. A. A. et al. "Wearable device for literacy activities with people with down syndrome". In: 2017 IEEE MIT Undergraduate Research Technology Conference (URTC), 2017, Cambridge. 2017 IEEE MIT Undergraduate Research Technology Conference (URTC), 2017. p. 1. 